\title{
SECCA procedure for anal incontinence and antibiotic treatment: a case report of anal abscess
}

\author{
Francesca Mandolfino ${ }^{1}$, Rosario Fornaro ${ }^{1}$, Cesare Stabilini ${ }^{1}$, Marco Casaccia ${ }^{1}$, Tommaso Testa ${ }^{2}$ \\ and Marco Frascio ${ }^{1 *}$ D
}

\begin{abstract}
Background: Fecal Incontinence (FI) can seriously affect quality of life. The treatment of fecal incontinence starts conservatively but in case of failure, different surgical approaches may be proposed to the patient. Recently several not invasive approaches have been developed. One of these is the radiofrequency (RF) energy application to the internal anal sphincter.

Case presentation: We report a rare case of an anal abscess related to a SECCA procedure in a 66-year-old woman affected by gas and $\mathrm{Fl}$ for twenty years.

Conclusions: The complications post-SECCA procedure reported in literature are generally not serious and often self-limited, such as bleeding or anal pain. This is a case of an anal abscess.

We suggest that this finding could consolidate the importance of administering antibiotic therapy to patients and to run a full course of at least 6 days rather than a short-term $(24 \mathrm{~h})$ therapy, with the aim to minimize the incidence of this complication.
\end{abstract}

Keywords: SECCA procedure, Fecal incontinence, Anal abscess, Antibiotic treatment, Radiofrequency complication

\section{Background}

Fecal incontinence (FI) is usually defined as the unintentional passing of stool in an inappropriate place or time more than two times a month. FI represents a worldwide problem affecting up to $12 \%$ of the general population and although is not considered a life-threatening disorder, it can seriously impair the quality of life of patients, frequently resulting in handicap [1, 2]. This disease is often under-diagnosed, under-reported and poorly managed. FI morbidity increases with age and is frequently observed up to $45 \%$ in over 70 years old population [3]. Treatment of FI is usually stratified from conservative to surgical treatments. The first approach starts with a fiber-enriched diet, physiotherapy of the pelvic floor and medication inducing constipation. When unsuccessful, a sphincter repair can be offered to patients presenting an anal sphincter defect. So

\footnotetext{
* Correspondence: mfrascio@unige.it

${ }^{1}$ Dipartimento di Scienze Chirurgiche e Diagnostiche Integrate (DISC),

Università degli Studi di Genova, Largo R. Benzi, 8, Genoa, Italy

Full list of author information is available at the end of the article
}

far, the available surgical procedures include dynamic graciloplasty [4], sacral neuromodulation [5] and artificial bowel sphincter [6]. However, these treatments are often not completely satisfactory, carry considerable side effects and demand specific expertise. Moreover, data obtained in randomized trials are currently limited, and reliable guidelines for the optimal treatment of FI are still lacking. Current practice guidelines for FI treatment are mainly based on expert opinions, clinical experience, and case studies [7]. Recently, less invasive approaches for the treatment of FI have been developed. One of these is the application of RF energy to the internal anal sphincter, the SECCA procedure. For the last two decades RF energy has been already used to treat gastroesophageal reflux disease, prostatic hypertrophy, sleep apnea syndrome, ablation of hepatic tumors, spinal lesions, renal tumors, and joint capsule instability [8].

The SECCA procedure works on the principle that, once applied on the affected area, it induces modifications of the internal anal sphincter structure that should

(c) The Author(s). 2018 Open Access This article is distributed under the terms of the Creative Commons Attribution 4.0 International License (http://creativecommons.org/licenses/by/4.0/), which permits unrestricted use, distribution, and reproduction in any medium, provided you give appropriate credit to the original author(s) and the source, provide a link to the Creative Commons license, and indicate if changes were made. The Creative Commons Public Domain Dedication waiver (http://creativecommons.org/publicdomain/zero/1.0/) applies to the data made available in this article, unless otherwise stated. 

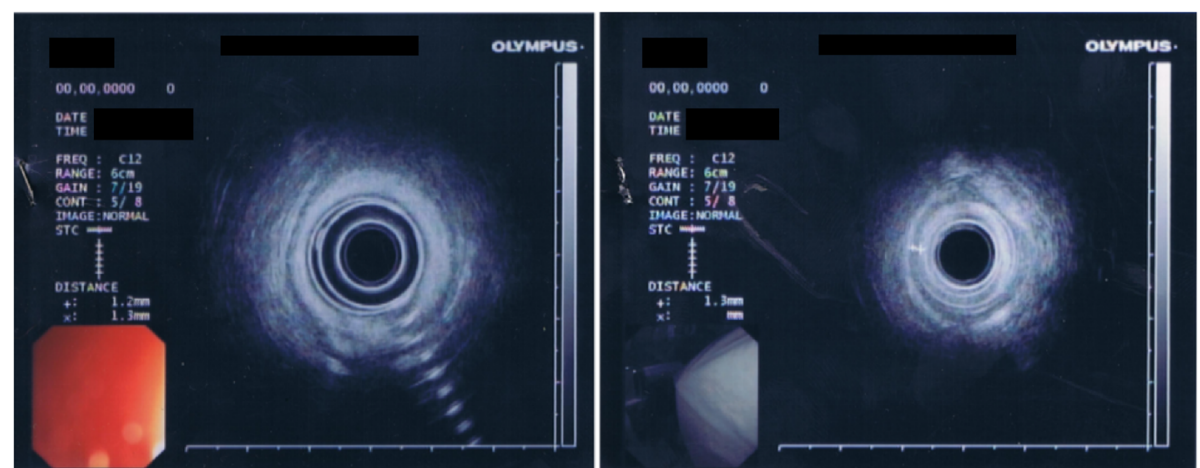

Fig. 1 Transrectal endoscopic ultrasonography (TRUS). TRUS examination shows external anal sphincter echo structural normal. Internal anal sphincter without interruption of continuity, but of reduced thickness, about $1.3 \mathrm{~mm}$ measured at about 9 o'clock and 3 in correspondence of the middle part of the anal canal

cause collagen deposition and fibrosis with the potential effect of tightening of the affected area. In particular, RF energy results in vibration of water molecules and subsequent frictional heating when delivered to a tissue in the frequency range of $200 \mathrm{kHz}$ to $3.3 \mathrm{MHz}$ [9-11]. Application of SECCA procedure in an animal model appeared to induce morphological changes in the internal and external anal sphincters leading to an anatomical state reminiscent of normal sphincter structure [12]. Thus, the SECCA procedure provides the release of temperature/impedance controlled RF energy to the sphincteric complex of the anal canal. In particular, the application of RF involves the anal canal up to $2.5 \mathrm{~cm}$ from the dentate line. The SECCA handpiece is an anoscopic device with four nickel-titanium curved needle electrodes (22 gauge, $6 \mathrm{~mm}$ in length) that are deployed through the mucosa of the anal canal into the internal anal sphincter muscle. The device is rotated four times of $90^{\circ}$ in order to treat all the surface of the anal canal [8]. Major contraindications for the SECCA treatment are the anal Crohn disease [13, 14] and distal ulcerative colitis, as well as previous in loco radiotherapy (RXT). While bowel inflammatory diseases are contraindicated for local inflammatory status, RXT is contraindicated for the alterations induced in the tissue architecture of the anal canal.
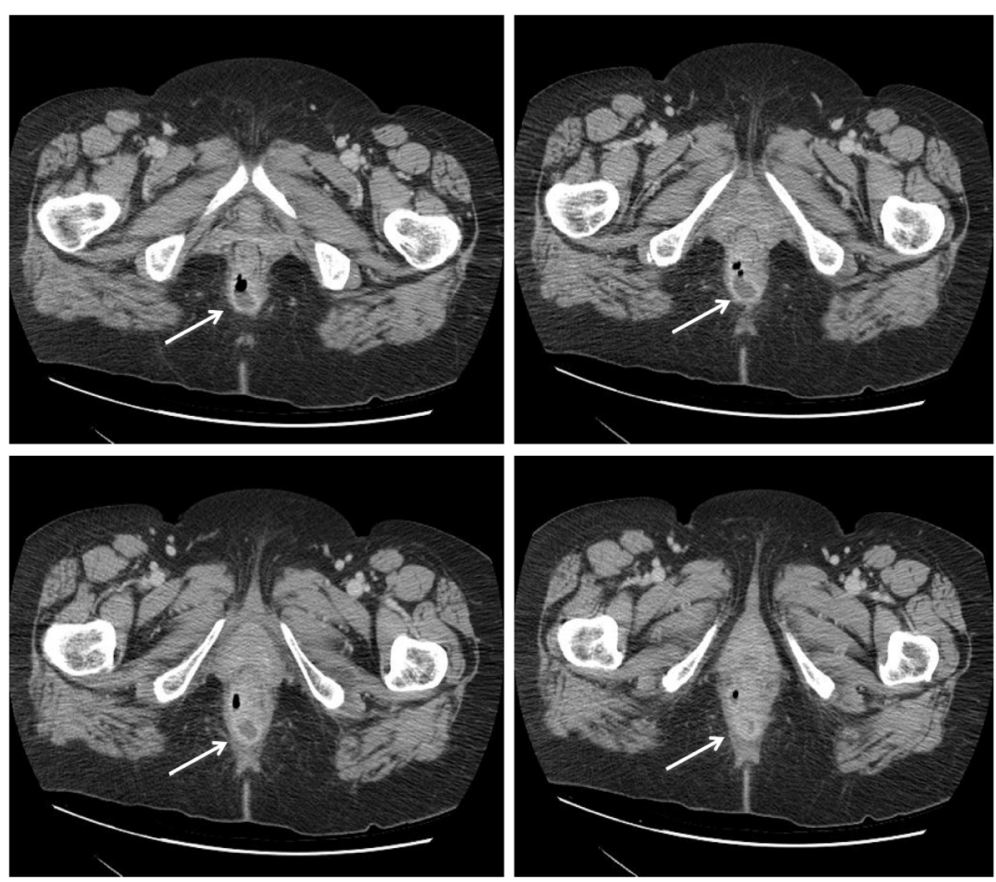

Fig. 2 Abdominal CT scan. CT scan shows a small perianal lesion (32×30×28mm approximately) in the right posterior-lateral wall with hyperemic wall and partial gas content, probably an abscess (arrows). No free fluid in the pelvis 

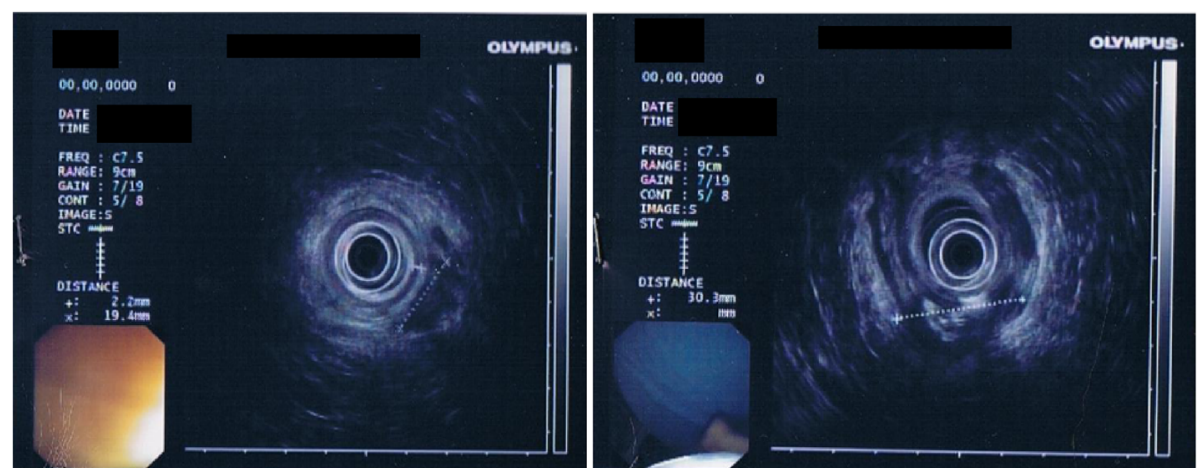

Fig. 3 Transrectal endoscopic ultrasonography (TRUS). TRUS was performed to assess the extent of the abscess. TRUS shows normal endoscopic appearance of the rectal mucosa. Internal anal sphincter appears seamless continuity but with a thickness of about $2.2 \mathrm{~mm}$. It was confirmed, in the right posterior-lateral area, the presence of an abscess $30 \times 15 \mathrm{~mm}$ hypoechoic with hyperechoic images suggesting gas content

\section{Case presentation}

A 66 year-old woman presented with gas and FI for twenty years. She has one daughter, born in 1970 by cesarean section after a long labor without pelvic lesions or lacerations. She takes the following home therapy:

Telmisartan $40 \mathrm{mg}, 1$ tablet at $12 \mathrm{~h}$ and 1 tablet at $20 \mathrm{~h}$; Levotiroxine $75 \mathrm{mcg}, 1$ tablet at $8 \mathrm{~h}$;

Bromazepam 1,5 mg, 1 tablet at $8 \mathrm{~h}$ and 1 tablet at $20 \mathrm{~h}$; Clomipramine $10 \mathrm{mg}, 1$ tablet at $8 \mathrm{~h}$;

Nebivol $5 \mathrm{mg}, 1$ tablet at $8 \mathrm{~h}$.

She refers FI of liquid or solid stool and gas incontinence two-three times per day, which had a marked negative impact on her social life. She is suffering from anxiety-depressive syndrome that worsened because of incontinence. She has changed her lifestyle, her behavior and she is very embarrassed of her incontinence.

Physical examination: nothing to report.

Rectal exploration: anal sphincter hypotonia.

Anorectal manometry was performed with detection of:
- Low median basal pressure: $20 \mathrm{mmHg}$ (normal range $40-60 \mathrm{mmHg}$ ),

- The lower limit of normal pressure after maximal voluntary contraction: $93 \mathrm{mmHg}$,

- Duration of maximal voluntary contraction $15 \mathrm{~s}$ (normally more than $1 \mathrm{~min}$ ),

- Sensitivity threshold to $30 \mathrm{ml}$ (normally $40-60 \mathrm{ml}$ ),

- Threshold of subjective reflection to $40 \mathrm{ml}$ (normal value $50-70 \mathrm{ml}$ ),

- Normal threshold of the inhibitory objective reflex: $40 \mathrm{ml}$ (normal value 30-50 ml) (Fig. 1).

She did not perform any medical therapy for incontinence but she has performed 3 cycles of rehabilitation with anorectal biofeedback with poor benefit.

We proposed to the patient to undergo SECCA procedure.

Lithotomy position, general anesthesia was performed. A dose of $500 \mathrm{mg}$ of metronidazole was administered intravenously to induction of anesthesia. Then, 20 applications of RF through the 4 nickel needles of the device were performed from the dentate line and proceeding cranially every $5 \mathrm{~mm}$ to $2.5 \mathrm{~cm}$ total. The same procedure was performed on the 4 quadrants of

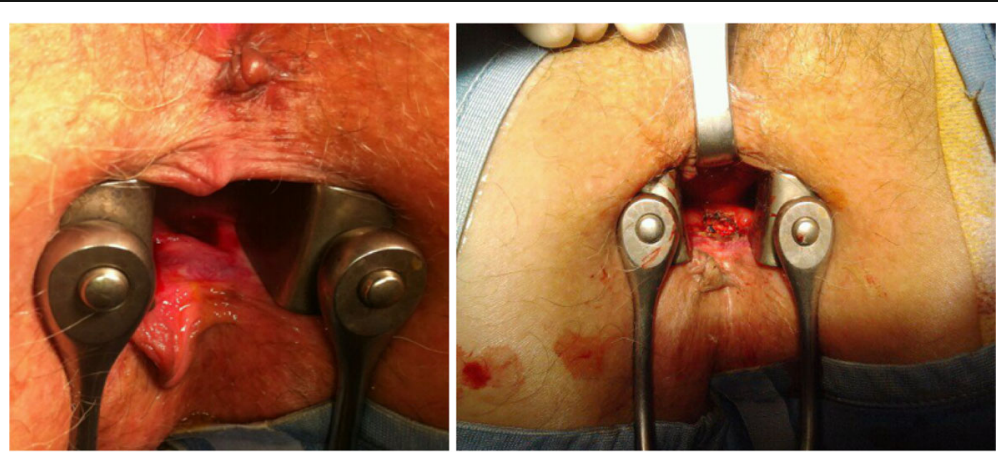

Fig. 4 Surgical removal of the abscess. Opening and deroofing with curettage of the fundus treated the abscess 
the internal anal sphincter, including the recto-vaginal wall (which is often the thinnest area and for this reason not always surgically treatable). The entire procedure lasted $40 \mathrm{~min}$.

The day after surgery she was discharged in good health. After 10 days she presented intermittent hyperpyrexia, leak of purulent material through the anus and anal pain. We performed general physical and proctologic examination with anoscope and found evidence of abscess of the right posterior-lateral anal wall at $2 \mathrm{~cm}$ from the anal verge. We have sent the purulent material for bacterial culture and antibiogram: "Escherichia coli multi resistant". The patient has performed blood tests without indices of inflammation replaying (Figs. 2 and 3). The authors administered antibiotic therapy with metronidazole and ciprofloxacin without satisfactory improvement of the symptoms.

Surgery has been organized to remove the abscess after 20 days from SECCA procedure.

The patient was in lithotomy position. Metronidazole $500 \mathrm{mg}$ was administered intravenously. The authors explored the anal canal finding about $2 \mathrm{~cm}$ from the anal verge, a recess of about $2-3 \mathrm{~cm}$ in diameter, undermined for about $1 \mathrm{~cm}$ in cranial direction. Opening and deroofing with curettage of the fundus treated the abscess (Fig. 4).

The day after surgery she was discharged in good health. Four days after the procedure, the patient was in good conditions. At 6 months follow up the patient was in good health and during the anal exploration it was possible to feel a rectal depression in the wall with a smooth consistence. In spite of the complication and subsequent surgical treatment, the procedure has been able to ameliorate the patient incontinence.

\section{Discussion and conclusion}

Among the complications post-SECCA procedure, the finding of an anal abscess is rarely described in the literature [8]. Antibiotic therapy was not sufficient to treat the abscess but it was necessary a surgical treatment to cure this complication.

This case seems to consolidate the importance of administering antibiotic therapy to patients treated with SECCA procedure. We propose to run a full course (at least 6 days) rather than a short induction therapy, with the aim to minimize the incidence of complications.

\section{Abbreviations}

CT: Computed tomography; Fl: Fecal incontinence; RF: Radiofrequency; RXT: Radiotherapy; TRUS: Transrectal ultrasound

\section{Acknowledgements}

We thank Dr. Katia Cortese for manuscript editing.

\section{Availability of data and materials}

All data generated or analyzed during this study are included in this published article.

\section{Authors' contributions}

FM: Management of the case and preparing the manuscript. RF, CS, MC: Management of the case and critical appraisal and review of the manuscript. TT: Interpretation of CT scan and ultrasonography. MF: Management of the case, critical appraisal and review of the manuscript. All authors read and approved the final manuscript.

\section{Ethics approval and consent to participate}

Written informed consent was obtained from the patient to participate in this study. A copy of the written consent is available for review by the Editor-in-Chief of this journal. The patient was one of the cases included in a study of the efficacy of the SECCA procedure [11] and was approved by the Regional Ethical Committee (authorization number 338REG2014).

\section{Consent for publication}

Written informed consent was obtained from the patient for publication of this case report and any accompanying images. A copy of the written consent is available for review by the Editor-in-Chief of this journal.

\section{Competing interests}

Francesca Mandolfino, Rosario Fornaro, Cesare Stabilini, Marco Casaccia, Tommaso Testa and Marco Frascio declare that they have no competing interests.

\section{Publisher's Note}

Springer Nature remains neutral with regard to jurisdictional claims in published maps and institutional affiliations.

\section{Author details}

'Dipartimento di Scienze Chirurgiche e Diagnostiche Integrate (DISC), Università degli Studi di Genova, Largo R. Benzi, 8, Genoa, Italy. ${ }^{2}$ IRCCS Azienda Ospedaliera Universitaria Policlinico San Martino-IST, Largo R. Benzi, 8, Genoa, Italy.

Received: 2 May 2018 Accepted: 1 August 2018

Published online: 07 August 2018

\section{References}

1. Nelson R, Norton N, Cautley E, Furner S. Community-based prevalence of anal incontinence. JAMA. 1995;274(7):559-61.

2. Whitehead WE, Norton NJ, Wald A. Introduction. Advancing the treatment of fecal and urinary incontinence through research. Gastroenterol. 2004; 126(1 Suppl 1):S1-2.

3. Herman RMSJ. Radio-frequency anal remodeling- a new technique for fecal incontinence treatment. US Gastroenterol Rev Szczegóły. 2006;2:34-5.

4. Chapman AE, Geerdes B, Hewett P, Young J, Eyers T, Kiroff G, Maddern GJ. Systematic review of dynamic graciloplasty in the treatment of faecal incontinence. Br J Surg. 2002;89(2):138-53.

5. Kapoor DS, Thakar R, Sultan AH. Combined urinary and faecal incontinence. Int Urogynecol J Pelvic Floor Dysfunct. 2005;16(4):321-8.

6. Belyaev O, Muller C, Uhl W. Neosphincter surgery for fecal incontinence: a critical and unbiased review of the relevant literature. Surg Today. 2006; 36(4):295-303.

7. Takahashi-Monroy T, Morales M, Garcia-Osogobio S, Valdovinos MA, Belmonte C, Barreto C, Zarate X, Bada O, Velasco L. SECCA procedure for the treatment of fecal incontinence: results of five-year follow-up. Dis Colon Rectum. 2008;51(3):355-9.

8. Ruiz D, Pinto RA, Hull TL, Efron JE, Wexner SD. Does the radiofrequency procedure for fecal incontinence improve quality of life and incontinence at 1-year follow-up? Dis Colon Rectum. 2010;53(7):1041-6.

9. Parisien CJ, Corman ML. The Secca procedure for the treatment of fecal incontinence: definitive therapy or short-term solution. Clin Colon Rectal Surg. 2005;18(1):42-5.

10. Frascio M, Mandolfino F, Imperatore M, Stabilini C, Fornaro R, Gianetta E, Wexner SD. The SECCA procedure for faecal incontinence: a review. Colorectal Dis. 2014;16(3):167-72.

11. Frascio M, Stabilini C, Casaccia M, Testa T, Fornaro R, Parodi MC, Marrone C, Gianetta E, Mandolfino F. Radiofrequency procedure (SECCA(R)) for fecal incontinence: one-year experience. Surg Technol Int. 2017;30:97-101.

12. Herman RM, Berho M, Murawski M, Nowakowski M, Rys J, Schwarz T, Wojtysiak D, Wexner SD. Defining the histopathological changes induced by 
nonablative radiofrequency treatment of faecal incontinence--a blinded assessment in an animal model. Colorectal Dis. 2015;17(5):433-40.

13. Fornaro R, Frascio M, Denegri A, Stabilini C, Impenatore M, Mandolfino F, Lazzara F, Gianetta E. Chron's disease and cancer. Ann Ital Chir. 2009;80(2): $119-25$

14. Fornaro R, Frascio M, Stabilini C, Sticchi C, Barberis A, Denegri A, Ricci B, Azzinnaro A, Lazzara F, Gianetta E. Crohn's disease surgery: problems of postoperative recurrence. Chir Ital. 2008;60(6):761-81.

Ready to submit your research? Choose BMC and benefit from:

- fast, convenient online submission

- thorough peer review by experienced researchers in your field

- rapid publication on acceptance

- support for research data, including large and complex data types

- gold Open Access which fosters wider collaboration and increased citations

- maximum visibility for your research: over $100 \mathrm{M}$ website views per year

At $B M C$, research is always in progress.

Learn more biomedcentral.com/submissions 